\title{
Understanding Logarithm: What are the Difficulties That Students Have?
}

\author{
Mayang Dintarini \\ University of Muhammadiyah Malang \\ mayangdintarini@umm.ac.id
}

\begin{abstract}
This study aims at determining students' difficulties in understanding logarithm material. The subject of this study are 10th grade students. The type of research is qualitative descriptive, and it applied several steps in the form of providing test to the students, determining the difficulties and interviewing students who had difficulty on the material. The result of the study showed that there were several difficulties such as applying definition, determining logarithmic properties to solve problems, applying logarithmic properties and applying the prerequisite material. These difficulties are due to the lack of understanding of logarithmic definitions, the lack of ability to see the facts relating to problems, over-focus on facts of rote and technical procedures, relying on improper intuition, and inconsistencies in symbolic writing and inaccuracy.
\end{abstract}

Keywords: difficulty, logarithm, causes

\section{INTRODUCTION}

The logarithm is important in learning since it can be applied in various fields such as science, computer, finance, industry and others. For example in finance, logarithm is used in compound interest problems. If M0 is the initial deposit, $\mathrm{Mn}$ is the deposit in the nth month, $\mathrm{i}$ is the interest rate, and $n$ is the mth month, where $m$ is the original number, then $\mathrm{Mn}=\mathrm{M} 0(1+\mathrm{i}) \mathrm{n}$. To find $\mathrm{n}$, we need a logarithm to facilitate the calculation, ie $=$ $\frac{\log M_{n}}{\log (1+i)}=\log _{(1+i)} M_{n}$.

Logarithms is one material that is difficult for students [1]. Another study on the difficulties in learning logarithms said that students are more focused on the procedural approaches and depended too much on rules rather than the concept of logarithm itself[2].Other study revealed that students often see log notations as an object, not an operation[3]. Therefore, students often do cancelation on a logarithmic form. For example, $\ln (7 \mathrm{x}-$ 12) $=2 \ln x$, becomes $(7 x-12)=2 x$. Students seemed to be able to perform the routine calculation but they were unable to answer the questions that required a higher level of thinking[1]. Many errors were not due to lack of knowledge, but it seemed to be based on the overgeneralization of algebraic rules.

Difficulties and frustrations to mathematics have been felt by many people long ago. Many students feel not confident even afraid of dealing with math. Many studies have written about the students' difficulties in learning mathematics, and it is followed by the decreasing interest to continue learning math to higher levels, such as research conducted [4], and[5]. Other researcher states that "The most commonly offered reason for declining participation in mathematics (given by almost $60 \%$ of respondents) is that the respondents considered mathematics difficult"[6]. Similar studies focus on several factors such as pedagogical factors and classroom practice have been made to identify that mathematics is "boring" and "difficult" by many students[7], [8].

According to Gagne, difficulties can lie in the four mathematical objects namely facts, concepts, principles and skills. Facts are agreements in mathematics, such as symbols and notations. For example the notation of the inverse exponent function $y=a^{x}$ is $y=\log _{a} x$. The concept is an abstract idea that allows one to classify an object and explain whether the object is an example or not an example of the abstract idea. The example of concept in logarithm is $\log _{a} b=c \Leftrightarrow a^{c}=b$. The principle is a composite of two or more concepts, which we usually call by theorems or postulate or properties. The example of principle in logarithms is $\log _{a} b c=$ $\log _{a} b+\log _{a} c$. While skills are procedures or rules to obtain or obtain a certain result.

If these difficulties occur at the elementary level students, and ongoing to the next level, students will feel unconfidence, frustration, boredom, panic, fear and so on. Students will also feel difficult to understand the next material. This is expressed by [9] that is many reasons to get a bad score in any subject. However, math such as house of cards, cards at the very bottom should be built solidly and accurately so it will support the next level. Each level depends on the previous level.

Other causes of learning difficulties are categorized in epistemological causes (referring to the natural difficulties and the abstracts of mathematical concepts), psychologically causes(referring to the students' selfreasons), and pedagogical causes (the reasons for teaching)[10].Based on the above explanation the researcher is interested in examining the difficulties of students in understanding the logarithm with the purpose of describing the causes of difficulties experienced by students in understanding logarithm.

\section{METHOD}

The type of this research is descriptive qualitative. At the beginning of the study, researcher conducted observations to determine the subject of research. The 
subject of this research was 10th grade students of SMAN 5 Malang who faced difficulties in logarithm, had the ability to write the process of the problem clearly and communicate orally well. A test was given to the students to determine the difficulties in understanding logarithm. Then an interview was given to students to make sure of the difficulties and it causes.

\section{RESULT}

Based on the results of tests and interviews, there are several causes of students' difficulties in understanding logarithms. The cause of the difficulty is as follows.

\section{Less understanding of the definition of logarithms}

In this study, researcher found some students did not fully understand the definition of logarithms. Eventually, the students found it difficult to apply the logarithmic definition to the problem. At first, the students seemed to able to calculate the logarithm value of a number, but when they failed when they confronted more complex logarithms.

For example Subject 4, Subject 4 was able to explain $\log _{4} 16=2$, but he was unable to explain how he got $\log _{4} \frac{1}{4}=-1$. Subject 4 was able to explain $\log _{4} 16=$ 2 with the definition " 4 to the power of what equal to 16 , then his answer was 2". But when he tried to explain $\log _{4} \frac{1}{4}=-1$, Subject 4 found no matching rules to support his answer. Even Subject 4 tried to make its own definition, which was "4 times (-1) ...". "4 times (-1) ..." was not the answer he wanted to explain why $\log _{4} \frac{1}{4}=$ -1 . Because Subject 4 knew that $4 \times(-1)=-4$. So he admitted that he did not understand the definition of logarithms yet.

This finding is similar to previous study which described that the students often failed to see logarithms as a number. It means that students often do not understand the meaning of logarithm[1]. When there is a "logarithmic expression, the small number is the base, the number after the log is the result of the logarithm and the number on the other side of the equal sign is the exponent". The expression gives the students a wrong idea about logarithm; they perceive a logarithmic form in some separate parts. Another study found that the lack of understanding on basic knowledge had become one of the causes of the students' problem[10]. In this case, the definition of the logarithm is the base of the material of logarithm. By understanding the logarithmic definition, students can derive the properties of logarithms without having to memorize those all.

The inability of students to see the relation of facts in the matter

The inability of students to see the relation of facts in the matter causes students often have difficulty in determining the properties of logarithms that can be used to solve the problem. For example, Subject 1 and Subject 2 could not determine the properties that can be used to convert $\log _{6} 15$ to the form oflog 23 and $\log _{3} 5$. Subject 1 wrotelog $615=\log _{2} 3+\log _{2} 5+\log _{3} 3+\log _{3} 5$, and subject 2 wrotelog $615=\log _{2} 3 . \log _{2} 5+\log _{3} 3 . \log _{3} 5$. Subject 1 and Subject 2 are connected only by what is known and intuitively asked. It is similar to Posamentier who stated that students have small theories about mathematics related to their learning[11]. According to Fischbein, an intuitive interpretation based on a primitive, limited, and entrenched experience is the one that destroys the formal control or the terms of the algorithmic settlement, and then precludes the correct mathematical reactions[11].

The ability of students to see these facts is one of the stages of mathematical reasoning. The ability to see the interconnected facts in solving this problem was the first stage of reasoning. This indicates a lack of reasoning levels of Subject 1 and Subject 2. Hiebert and Carpenter say that the degree of understanding is determined by the number and strength of connections[12].

\section{Over focus on the memorizing facts and procedural}

While working on the problem of logarithms, students are often constrained by the many logarithmic properties and difficult for them to memorize. The constraint makes it difficult for students to understand logarithms, due to over-focusing on the theorems or properties they need to memorize. Students are ultimately not trying to develop their reasoning.

All subjects have difficulty in applying logarithms on tests. These was because the subject was still thinking to memorize formulas and procedures, and not trying to reasoning. For example Subject 3 , he has difficulty in applying the properties of logarithms. Subject 3 changed $\log _{6} 15$ to $\frac{\log 6}{\log 15}$. The same error was done by Subject 2 , he changed $\log _{2} 5$ to $\frac{\log _{2} 2}{\log _{2} 5}$. Similarly, Subject 4 and Subject 5, researchers found the same error. Subject 1, Subject 2, Subject3, Subject4, and Subject 5 tried to use his memory of the properties of logarithms that he wants to use. But, they were failed in remembering that properties. The subject did not try to seek or rediscover the properties. They were over focused and overconfident in their memories.

The finding matched the assumption that the inaccuracy may be the cause due to the lack of understanding and skill of the algorithm[13]. The condition refers to an error due to lack of understanding, where students used incorrect rules[14].

\section{Rely on intuition}

Students' intuition in answering the questions resulted in different answers. Those answers were not based on the logarithmic properties. Intuition will be useful if delivering the correct answer, but if the answer is wrong, the student should not use the intuition. For example, Figure 1 and Figure 2 are works of Subject 1 and Subject 2 based on their wrong intuition.

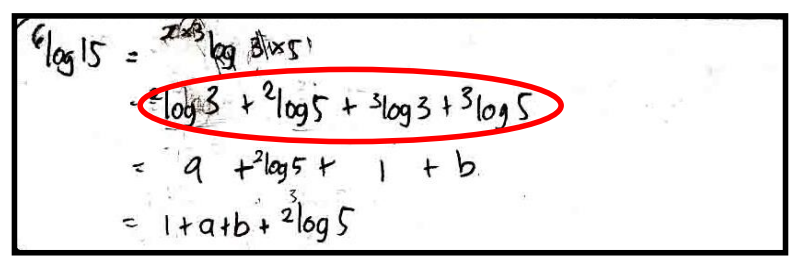

Figure 1. subject 1's test result 


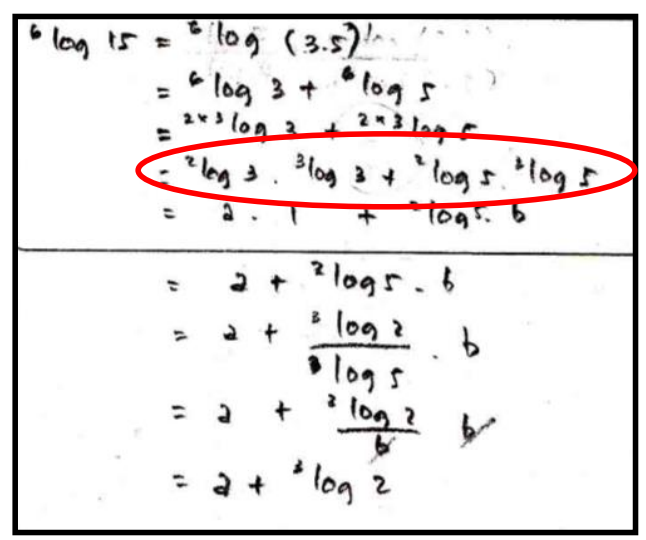

Figure 2. subject 2's test result

Fischbein and Barash developed a theory of students' mathematical performance analysis. In this theory, they suggest there are three components of knowledge, namely: algorithm, formal and intuitive. The algorithm is the ability to use the procedure according to the theory. This ability sharpens the problem-solving ability and understanding of "why to use the procedure". The formal components include axioms, definitions, theorems, and proofs. It relates to rigidity and consistency in deductive reasoning and free of the limitations imposed by concrete and practical situations. And intuitive is described immediately, instilling the feeling that there is no need to prove it to test its intuition[11].

Sometimes these three components converge, but usually in the process of learning, understanding, and problem solving, interaction conflicts will arise. Often intuitive knowledge manipulates and masks formal interpretation or use of algorithmic procedures.

\section{Inconsistent in writing symbols and inaccuracies}

Often students are not consistent in writing mathematical symbols. The inconsistency results in students having difficulty solving logarithmic problems. For example Subject 4 wrote $\log _{3} 6$ as $\log _{3} 3 . \log _{3} 2$, whereas Subject 4 actually realized the meaning of point (.)there was the sum (+). However, in the end, Subject 4 encountered errors due to this inconsistency.

$$
\frac{\log _{3} 2 \cdot \log _{3} 3}{\log _{3} 3 \cdot \log _{3} 5}=\frac{\log _{3} 2 \cdot \log _{3} 3}{\log _{3} 3 \cdot \log _{3} 5}
$$

Several students' errors in aspects of variables include a) labeling, a changing value, or a verb for variables and constants; b) misunderstanding of the concept of "unity" when faced with variables and c) Establishing the wrong equation or inequality[15]. These errors finding support the finding of this study that proves the students' difficulty in the writing of the symbols.

\section{CONCLUSION}

In this research, there are several causes of students' difficulties in understanding logarithms, namely lack of understanding about logarithmic definition, lack of ability to see the relation of facts to matter, too focused on the memorizing facts and procedural, relying on wrong intuition, inconsistencies in writing symbols and inaccuracies. The authors recommend further research on the choice of subjects should be based on the students' cognitive ability level (high-moderate-low).

\section{REFERENCES}

[1] C. B. Liang and E. Wood, "Working with Logarithms: Students' Misconceptions and Errors," Math. Educ., vol. 8, no. 2, pp. 53-70, 2005.

[2] T. Berezovski, "Manifold Nature Of Logarithms: Numbers, Operations And Functions," in PME-NA Vol.2-62, 2006.

[3] R. Yen, "Reflections on higher school certificate examinations: Learning from their mistakes, High School Certificate 1998," Reflections, vol. 24, no. 3, pp. 3-8, 1999.

[4] R. Holton, D., Muller, E., Oikkonen,J., Valenzuela, O. \& Zizhao, "Some Reasons For Change In Undergraduate Mathematics Enrolments," Int. J. Math. Educ. Sci. Technol., vol. 40, no. 1, pp. 3-15, 2009.

[5] F. Barrington, Participation in Year 12 Mathematics Across Australia 1995_2004No Title. 2006.

[6] S. Murray, "Declining Participation In Post Compulsory Secondary School Mathematics: Students' Views of And Solutions to The Problem," Res. Math. Educ., vol. 13, no. 3, pp. 269-285, 2011.

[7] T. Brown, M., Brown, P. \& Bibby, ““"I Would Rather Die",: Reasons Given By 16-Year-Olds For Not Continuing Their Study of Mathematics," Res. Math. Educ., vol. 10, no. 1, pp. 3-18, 2008.

[8] H. Mendick, "Mathematical stories: Why do more boys than girls choose to study mathematics at ASlevel in England?," Br. J. Sociol. Educ., vol. 26, no. 2, 2005.

[9] B. Butterworth, What Counts: How Every Brain Is Hardwired For Math. New York: Free Press, 1999.

[10] E. Bingolbali, "Multiple Solutions to Problems in Mathematics Teaching: Do Teachers Really Value Them ?," vol. 36, no. 1, 2011.

[11] G. Egodawatte, "Secondary School Students Misconceptions in," University of Toronto, 2011.

[12] S. E. Katsberg, "Understanding Mathematical Concepts: The Case Of The Logarithmic Function," University of Georgia, 2002.

[13] R. Widdiharto, Diagnosis Kesulitan Belajar Matematika SMP dan Alternatif Proses Remidinya. Yogyakarta: Pusat Pengembangan dan Pemberdayaan Pendidik dan Tenaga Kependidikan Matematika, 2008.

[14] et al Barrera, "Cognitive Abilities and Errors of Students in Secondary School in Algebraic Language Processes," North Am. Chapter Int. Gr. Psychol. Math. Educ., vol. 1, pp. 253-261, 2004.

[15] S. Pratama, "Kesalahan Siswa Kelas VII SMP dalam Aljabar dan Upaya Mengatasinya Menggunakan Scaffolding," Universitas Negeri Malang, 2014. 